Continuous monitoring of fall-out in New Zealand since 1959 has indeed shown that the contamination of rain by strontium-90 since the late fifties increased until the end of 1964 much as in the Northern Hemisphere. Since then there has been a gradual decline of contamination with the disappearance of debris from nuclear weapons from the stratosphere, and the French tests have so far added very little in the way of long-lived material to the contamination boing detected. In retrospect, it is remarkable how the deposition of radio-strontium in New Zealand has followed that in the Northern Hemisphere, though with a time lag and with a peak that never reached the same heights. No doubt the immediate consequences of the recent explosions in China will be less in the Southern Hemisphere than in the Northern.

\section{Cool Appraisal}

Superconductors have seemed for some time to offer attractive possibilities in power cables and transformers. It is argued that the greatly increased conductivity of cooled conductors or superconductors will more than make up for the cost of keeping them cool. Dr. K. J. R. Wilkinson, of the Central Research Laboratories of Associated Flectrical Industries, has now carried out an investigation of the economic and technical feasibility of the idea (Proc. Inst. Elec. Eng., 113, 1509; 1966) which is likely to moderate some enthusiasm for superconductors.

Dr. Wilkinson has compared the use of niobium at $4^{\circ} \mathrm{K}$ (a supcrconductor), aluminium at $20^{\circ} \mathrm{K}$ (with a resistivity of $3 \cdot 10^{-9} \mathrm{ohm} / \mathrm{cm}$ ) and beryllium at $77^{\circ} \mathrm{K}$ (with a resistivity of $2 \cdot 10^{-8} \mathrm{ohm} / \mathrm{cm}$ ). His basic design uses two concentric annular cooling jackets with an evacuated space between them containing two radiation shields. For the extreme case of niobium at $4^{\circ} \mathrm{K}$, Dr. Wilkinson shows that it will be more efficient to use several coolants for providing refrigeration, with the temperature dropping in smaller stages. The conductor would be in the form of a cylinder of niobium foil, with liquid helium circulating internally and liquid hydrogen and liquid nitrogen circulating externally. For the aluminium and beryllium conductors this design would be inadequate, and a wire stranded design is suggested.

Unfortunately, there seems little hope that the designs will ever be more than an academic exercise. The cost comparisons which Dr. Wilkinson makes show that only the niobium superconductor could be expected to offset its refrigeration costs by savings in conductor material and conduction losses. In this case, cost for a 3 phase circuit rated $760 \mathrm{MVA}$ at $275 \mathrm{kV}$ and 1,600 A would be about $£ 12,000 / \mathrm{km}$, against $£ 13,000 / \mathrm{km}$ for copper, but this takes no account of construction and laying costs, which would certainly be enormously increased. For aluminium and beryllium the costs are much greater and work out at $£ 24,000 / \mathrm{km}$ and $£ 800,000 / \mathrm{km}$ respectively. In addition to the cost disadvantage, cooled cables are very vulnerable both to accidental damage and to fault ovcrloads, and liquid hydrogen would represent a real hazard. For transformers the situation seems hardly more optimistic; although transformers wound with aluminium foil at $20^{\circ} \mathrm{K}$ might show a marginal advantage, this would be more than absorbed by the expenses of installing, housing and supervising the plant, and looking after the liquid hydrogen.

\section{Directory of Directorates}

UNESco has produced the first volume of a series intended to be a much enlarged revision of the Directory of National Science Research Councils first published ten ycars ago. The first volume of the new series deals with Europe and North America (World Directory of National Science Policy-Making Bodies, Vol. 1, Europe and North America, Francis Hodgson, Ltd., $£ 3$ 5s.). Later volumes will appear in the next few months. The intention is to include in the volumes those organizations which have a national responsibility for policymaking and the planning, organization and co-ordination of scientific and technological research. An attempt has been made to exclude bodies at "ministerial level" where they have responsibility not confined to planning and co-ordination of research, although clearly criteria for choice in this respect are bound to be exceedingly difficult to apply consistently.

\section{Mycoplasmas}

from a Correspondent in Microbiology

THE Society for General Microbiology in conjunction with the Pathological Society held a timely and stimulating symposium on mycoplasmas in London last week. Papers on fine structure, antigenicity and identification provided a basis for a discussion of the pathogenicity of these microbes and their effects on animal cells. D. Taylor-Robinson proposed that identification schemes should consider the source of isolates-avian, mammalian, tissue culture, and the like-and metabolic attributes of isolates, such as glucose or arginine fermentation and their antigenic structure. Identifications based upon only a few criteria are clearly equivocal. Similarly, extreme caution should be exercised when interpreting electron micrographs purporting to demonstrate mycoplasma-like particles in malignant human tissues. (A warning to this effect was issued recently by the World Health Organization.) Another urgent problem in the study of mycoplasmas is the correct diagnosis of strains as the causal agents of disease. It is surprising and, indeed, disappointing that, in many reports of the isolation of mycoplasmas from disease conditions, these organisms are stated categorically to be the causative agents even though the crucial re-infection tests have not been made. In this context the investigation of swine enzootic pneumonia, described at the meeting by R. F. W. Goodwin and P. Whittlestone, is encouraging and exemplary. These workers obtained a number of mycoplasmas from pneumonic pigs only some of which would induce the disease when inoculated into healthy animals. The causal mycoplasma of the enzootic condition, $M$. suipneumoniae, has very exacting growth requirements in comparison with other isolates. Thus the readily cultured and less fastidious types isolated from mixed mycoplasma populations may be wrongly identified as the pathogens, especially when the application of Koch's postulates is ignored.

Identification of causative factors is an acute problem in connexion with malignant and arthritic diseases. 